\title{
Biosynthesis, Characterization and Cytotoxicity of Zinc Nanoparticles Using Panax ginseng Roots, Araliaceae
}

\author{
Mustafa Nadhim Owaid ${ }^{* *}$, Tahseen Ali Zaidan², Rasim Farraj Muslim², Mohammed \\ Abdulrahman Hammood ${ }^{2}$ \\ 1 Ministry of Education, Department of Heet Education, Hit, Iraq. \\ 2 University Of Anbar, Department of Ecology, College of Applied Sciences-Hit, Hit, Anbar, Iraq.
}

\begin{abstract}
This study aims to biosynthesize zinc nanoparticles from the aqueous extract of Panax ginseng (Red Ginseng) roots. The characteristics of ZnNPs were checked using change in color, UV-Vis, SEM, SPM, AFM, FT-IR, and EDS analyses, and assessed their cytotoxicity against L2OB tumor cell line using MTT assay. The change in the solution color after $3 \mathrm{hr}$ on $70{ }^{\circ} \mathrm{C}$ is from yellow to the brownish color with whitish sediments. The adsorption peak of UV-vis is $340 \mathrm{~nm}$ as evidence of formation the Zn nanoparticles. AFM, SEM and EDS observe shapes of zinc nanoparticles which are spherical to irregular particles with rate of size $59.76 \mathrm{~nm}$. The concentration 100\% Zinc nanoparticles significantly $(p<0.01)$ recorded best inhibition percentage $41.70 \%$ against murine fibroblast cells (L2OB) which have receptors of human polioviruses. Thus, this work is considered as an auspicious first test to reduce the growth of cancers using green ZnNPs of Ginseng (Panax ginseng) in vitro.
\end{abstract}

Keywords: Anticancer activity, EDS, Red Ginseng, SPM, ZnNPs.

\section{INTRODUCTION}

Ginseng is one of Korean herbs which was used in ancient world ${ }^{1}$. The scientific name of Ginseng is Panax ginseng and it is a perennial plant belongs to the Araliaceae family ${ }^{2}$. The Greek word of Panax is meaning drug for all diseases, and its origin from two words the first pan and the second axos meaning "all" and "medicine" respectively ${ }^{3}$. Korean Red Ginseng has been using as a health food and food additives ${ }^{4}$ because of its potential role in the immune improvement ${ }^{5}$, anti-fatigue, anti-stress, anti-aging effects ${ }^{6}$, antifungal ${ }^{7}$, anti-diabetic ${ }^{8}$, anticancer activity ${ }^{9}$, and improvement of blood circulation, and serum cholesterol ${ }^{10}$.

*Corresponding author: Mustafa Nadhim Owaid, e-mail: mustafanowaid@gmail.com (Received 13 August 2018, accepted 20 September 2018) 
The chemical composition of Panax ginseng mainly consists from saponin (ginsenoside) ${ }^{4}$, water-soluble sugar, acidic polysaccharides, and phenolic compounds ${ }^{11}$, thus $P$. ginseng had numerous pharmacological and physiological roles and opens the door toward using its extracts as a green agent to synthesize metallic nanoparticles. Few studies have enabled to Ginseng-mediated synthesize silver nanoparticles and gold nanoparticles ${ }^{12-14}$.

Many studies were investigated the role of silver nanoparticles of Ginseng toward inhibiting human cancers which decreased the levels of mRNA and phosphorylation of receptors of epidermal growth factor in cancer cells ${ }^{12}$ while ${ }^{14}$ referred to antioxidant effects by gold nanoparticles biosynthesized from Ginseng. Silver and gold nanoparticles from leaves of this plant showed antimicrobial and potent anticoagulant agents ${ }^{13}$. In the last years, AuNPs were used as cosmetic products because of their role against inflammation, and to disinfect skin wounds ${ }^{14}$.

The use of bacteria, fungi, parts of plant and their enzymes and extracts for synthesis of zinc nanoparticles have much benefits for pharmaceutical and biomedical applications ${ }^{15}$. Also, ZnNPs are used as preservative for different products like foods, pigments, plastics, ceramics, glass, etc. ${ }^{16}$. Most of the studies of Red Ginseng roots have referred to testing the bioactivity of its nanoparticles such as AgNPs and AuNPs. However, this recent study firstly indicates that Red Ginseng reduced zinc sulfate heptahydrate $\left(\mathrm{ZnSO}_{4} \cdot 7 \mathrm{H}_{2} \mathrm{O}\right)$ and produce $\mathrm{ZnNPs}$ which inhibited mouse fibroblast cells (L2OB cell line) in vitro. As you know that murine fibroblast cells have receptors of human polioviruses thus this study is important in the medical field.

\section{METHODOLOGY}

\section{Red ginseng}

Dried Red Ginseng roots, Panax ginseng (Figure 1), were purchased from the local market in Ramadi, Iraq which was obtained in October 2017. The pieces of roots of Red Ginseng were grinded using the Stand Blender (SAMiX, model LB6105D, China) to get its powder which will use in the extraction.

\section{Extraction of Panax ginseng powder}

About $20 \mathrm{~g}$ of the powder of $P$. ginseng was extracted in $200 \mathrm{~mL}$ Distilled Water (DW) in a 500mL-flask using magnetic stirrer hot plate for 20 minutes at $100{ }^{\circ} \mathrm{C}$ then cooled to $25{ }^{\circ} \mathrm{C}$. The aqueous extract was filtered using filter paper Whatman No. 1 and then centrifuged for 10 minutes at 4000 cycle $/ \mathrm{min}$. The obtained aqueous extract was kept in the icebox as a stock solution until its use. The residue was emitted. FT-IR (Fourier Transform Infrared Spectroscopy) spectrum of this aqueous extract was performed for characterizing and com- 
pared with FT-IR spectrum of the biosynthesized ZnNPs from it later.

\section{Biosynthesis of zinc nanoparticles}

About $0.86 \mathrm{~g}$ of zinc sulfate heptahydrate $\left(\mathrm{ZnSO}_{4} \cdot 7 \mathrm{H}_{2} \mathrm{O}\right)$ was dissolved in $1 \mathrm{~L}$ of DW on the magnetic stirrer until the completion of dissolving was observed. The final concentration of $\mathrm{ZnSO}_{4} \cdot 7 \mathrm{H}_{2} \mathrm{O}$ solution is $3 \times 10^{-3} \mathrm{M}$. Only, $100 \mathrm{~mL}$ of zinc sulfate solution $3 \times 10^{-3} \mathrm{M}$ was mixed with $30 \mathrm{~mL}$ of the crude aqueous Ginseng extract and heated on the magnetic stirrer hotplate at $70{ }^{\circ} \mathrm{C}$ for $3 \mathrm{hr}$ to synthesize zinc nanoparticles. The same test was achieved at $25{ }^{\circ} \mathrm{C}$ for $24 \mathrm{hr}$. The change in the mixture color was individually recorded at $25^{\circ} \mathrm{C}$ and $70{ }^{\circ} \mathrm{C}$.

\section{Characterization of ZnNPs}

Ginseng-mediated biosynthesis of zinc nanoparticles (ZnNPs) was characterized using changing of the color of the mixture solution, UV-Visible spectrum (by EMC-LAB V-1100 digital spectroscopy, Germany), FT-IR spectroscopy, AFM, SPM, SEM, and EDS analyses.

\section{In vitro Cytotoxicity}

The cytotoxicity of ZnNPs toward L2OB tumor cell line was investigated by MTT assay as mentioned by ${ }^{17,18}$. Firstly, $100 \mu \mathrm{l} /$ well of $10^{6}$ cell $/ \mathrm{mL}$ L2OB cells was cultured in 96-well tissue culture plate. Three concentrations of 50\%, 75\%, and $100 \%$ of colloid ZnNPs and extract of Ginseng roots were seperately applied in this test. About one hundred microliters of each concentration was added within each well then incubated at $37^{\circ} \mathrm{C}$ for $48 \mathrm{hr}$. After that, $10 \mu \mathrm{l}$ of $5 \mathrm{mg} / \mathrm{mL}$ MTT solution (3-(4,5-dimethylthiazol-2-yl)-2.5-diphenyltetrazolium bromide) was added to each well and re-incubated at $37^{\circ} \mathrm{C}$ for $4 \mathrm{hr}$. Finally, $50 \mu \mathrm{l}$ dimethyl sulfoxide (DMSO) was added to each well and incubated for 10 minutes. L2OB cells were cultured in complete medium without ZnNPs or the extract of Ginseng solution as a control. ELISA reader was used to measure the absorbance of each well at $620 \mathrm{~nm}$. The growth inhibition percentage was calculated using the equation below to give the cytotoxicity:

Growth inhibition percentage $=\frac{(\text { Optical Density of control well }- \text { Optical Densityof treatment wells })}{\text { Optical Density of control well }} \times 100$

\section{Statistical analysis}

The data, in triplicates, has been subjected by its mean to one way analysis of variance (ANOVA) using SAS program, version 9. The significance of differences has been determined by using Duncan's Multiple Range Test and the probability least than 0.01 was considered to be statistically significant. 


\section{RESULTS AND DISCUSSION}

UV-Visible spectrum of the biosynthesized ZnNPs from $P$. ginseng and their color were checked in this test to confirm the formation of nanoparticles. The color change of the mixture solution from yellow to the pale yellow close of the brownish color with whitish sediments was apparently recorded in tube B at peak $340 \mathrm{~nm}$ (Figure 1). The color arises due to excitement of surface Plasmon vibration in ZnNPs. These results agree with ${ }^{19}$ who produced polydispersed brownish ZnNPs with absorbance peak at $310 \mathrm{~nm}$ using Actinomycestes. This case was achieved by the heating at $70^{\circ} \mathrm{C}$ for $3 \mathrm{hr}$ with absorption of $3.150 \mathrm{~cm}^{-1}$. The absorption of tube A (performed at the room temperature) is $2.620 \mathrm{~cm}^{-1}$ that less than $\mathrm{B}$ tube. The heating to $70{ }^{\circ} \mathrm{C}$ is more suitable than $25{ }^{\circ} \mathrm{C}$ for forming $\mathrm{ZnNPs}$ from Red Ginseng roots extract due to increase of activation energy to reduce this organic molecules ${ }^{20}$.

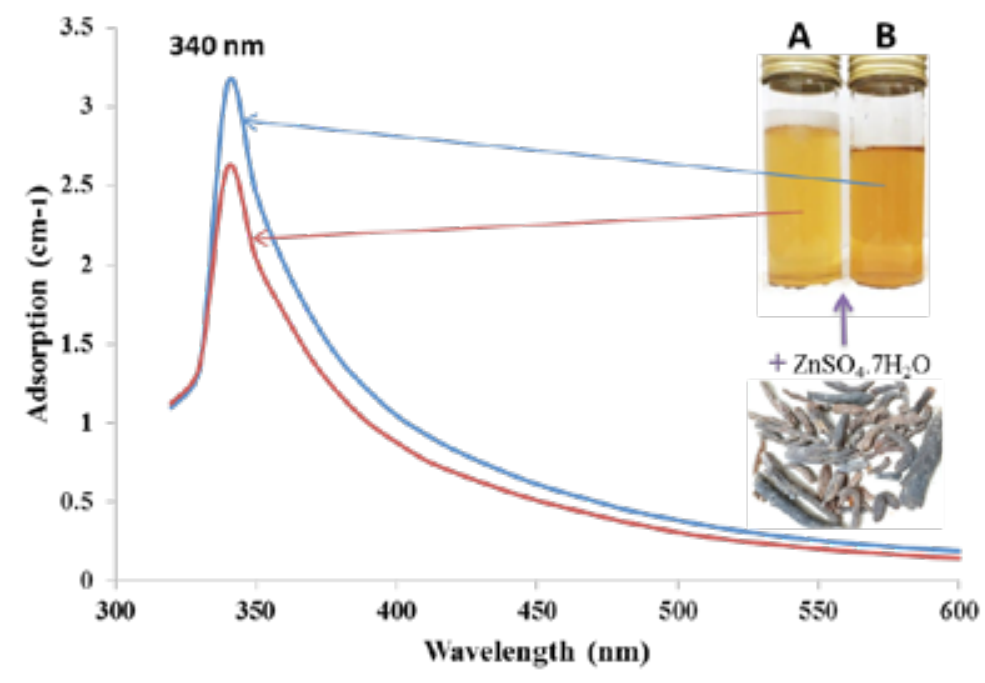

Figure 1. UV-Visible spectrum of the biosynthesized ZnNPs from $P$. ginseng extract using at $25^{\circ} \mathrm{C}(\mathrm{A})$ and $70^{\circ} \mathrm{C}(\mathrm{B})$.

SEM image (Figure 2) observes shapes of zinc nanoparticles which are spherical to irregular particles with a clear accumulation. Figure 3 shows histogram of the particle size distribution of the biosynthesized zinc nanoparticles which reach to average $59.76 \mathrm{~nm}$. Volumes of zinc nanoparticles of $45.00 \mathrm{~nm}, 60.00$ $\mathrm{nm}$, and $70.00 \mathrm{~nm}$ are $\leq 10 \%, \leq 50 \%$, and $\leq 90 \%$ respectively. The lower particles diameter is $45 \mathrm{~nm}$ while the higher diameter is $85 \mathrm{~nm}$ with volumes $8.16 \%$ and $1.53 \%$ respectively. The higher amount is $17.86 \%$ for the ZnNPs with the 
diameter of $65 \mathrm{~nm}$. Granularity Cumulation distribution of ZnNPs also has different accumulation according to their sizes as shown in Figure 3. The zinc nanoparticles of $45 \mathrm{~nm}$ have the lowest accumulation of $8.16 \%$, followed $18.88 \%$ and $36.73 \%$ for ZnNPs with diameters 50.00 and $55.00 \mathrm{~nm}$ respectively. The higher accumulation percentage is $100 \%$ for ZnNPs of $85.00 \mathrm{~nm}$ followed $98.47 \%$ and $92.35 \%$ for the sizes $80.00 \mathrm{~nm}$ and $75.00 \mathrm{~nm}$ respectively.



Figure 2. Scanning Electron Microscopy (SEM) of the biosynthesized zinc nanoparticles.

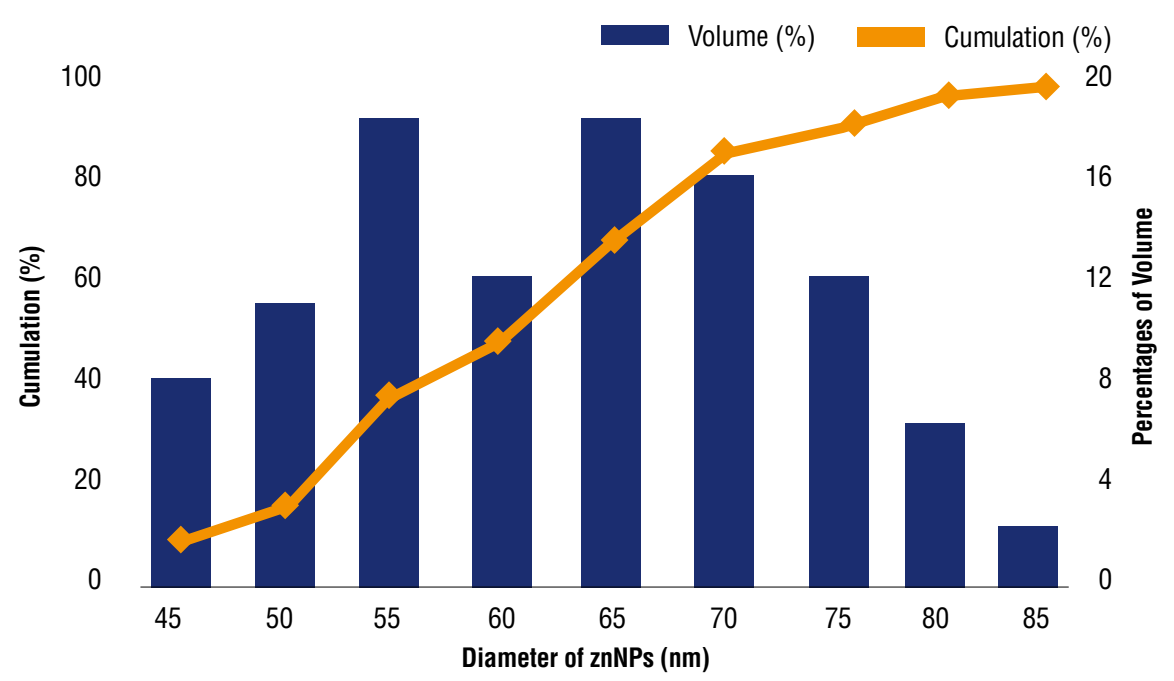

Figure 3. Histogram of particle size distribution of the biosynthesized zinc nanoparticles. 
AFM shows the lateral and three-dimensional images to screen surface roughness of the Ginseng-mediated zinc nanoparticles (ZnNPs) at size image $2042.09 \mathrm{~nm} \times 2052.20 \mathrm{~nm}$ as shown in Figure 4. Surface roughness analysis exhibits some functional parameters such as roughness average of $4.26 \mathrm{~nm}$, reduced summit height of $0.65 \mathrm{~nm}$, core roughness depth of $15.4 \mathrm{~nm}$, and reduced valley depth of $4.81 \mathrm{~nm}$. Hybrid parameters are measured like surface area ratio which reaches 7.75 and mean summit curvature reaches $0.43 \mathrm{~nm}^{-1}$. This is an indicator for the formation $\mathrm{Zn}$ nanoparticles in small sizes less than $60 \mathrm{~nm}$.

Figure 5 presented the Energy Dispersive X-ray (EDS) measurement which reconfirmed that the biosynthsized nanoparticles are actuality metal ZnNPs. The existence of carbon, phosphor, sulfur and oxygen peaks observed the presence of covering organic fractions of Ginseng on the $\mathrm{Zn}$ nanoparticles. Weight of Zinc 3.84\% compared with $0.34 \%$ and $0.73 \%$ for S and P respectively. The presence of the elemental $\mathrm{Zn}$ can be seen in the EDS graph that indicates the reduction of $\mathrm{Zn}$ ions to elemental zinc. The appearance of other elements, like $\mathrm{K}$ after adsorption is from the organic moieties in the watery crude extract as mentioned by ${ }^{21}$ who confirmed that potassium is adsorbed on the surface of ZnNPs.

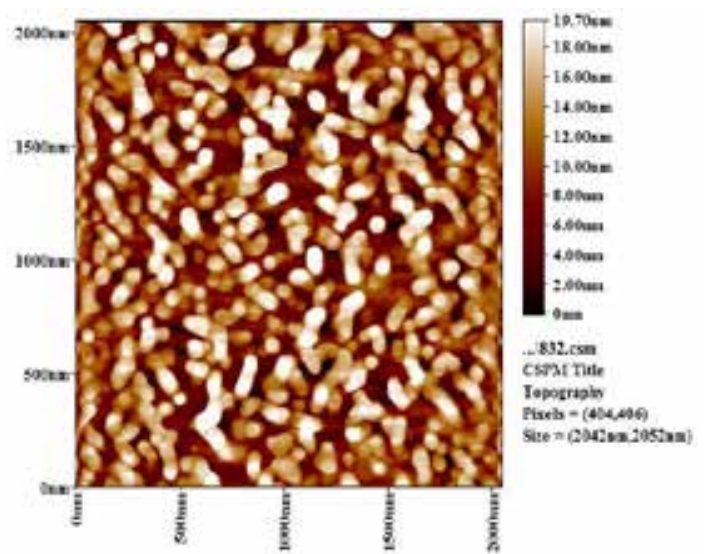

A

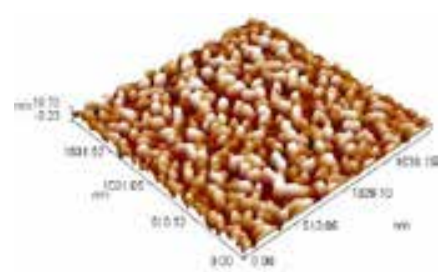

B

Figure 4. AFM of the biosynthesized ZnNPs lateral (A), three-dimensional (B). 


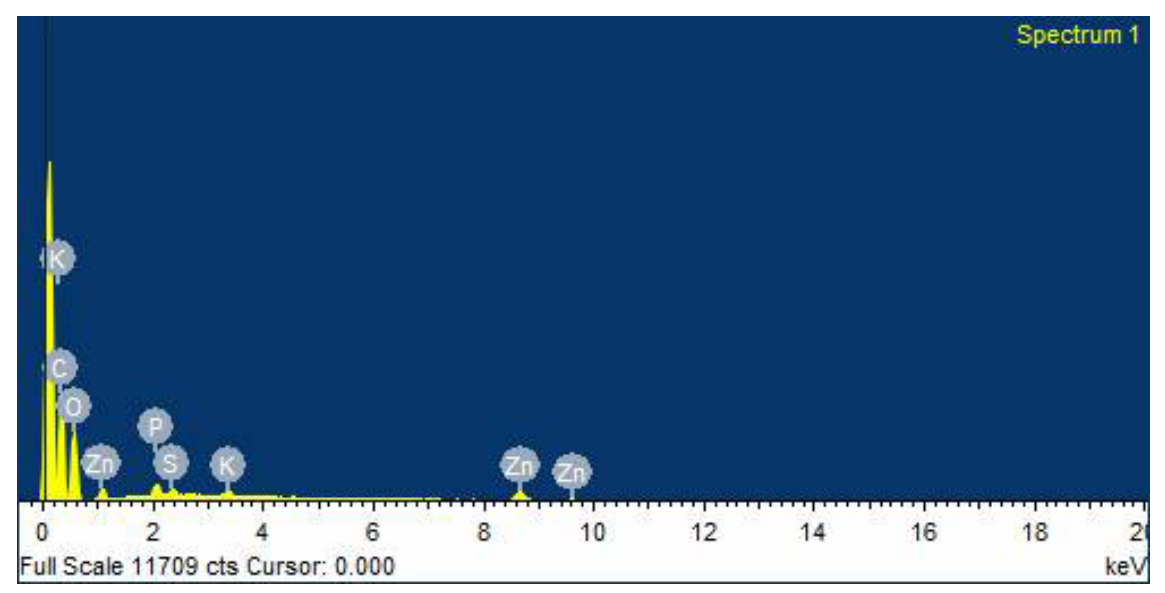

Figure 5. Energy Dispersive X-ray (EDS) spectrum of ZnNPs of Panax ginseng.

The FT-IR spectroscopy was used to determine the chemical composition and active groups found in the studied samples (Ginseng extract and the biosynthesized ZnNPs from this extract) (Figure 6). The FT-IR spectrum of the Ginseng extract presented in Figure 6A showed finding two peaks the first $765 \mathrm{~cm}^{-1}$ due to the covalent bond between carbon and silicon ( $\mathrm{Si}-\mathrm{C}$ ) and another peak $1107 \mathrm{~cm}^{-1}$, which is evidence of the oxygen bond with silicon in ( $\left.\mathrm{Si}-\mathrm{O}\right)$. As well as absorption peaks at $1359 \mathrm{~cm}^{-1}$ and $1419 \mathrm{~cm}^{-1}$ belong to the homogeneous and heterogeneous bending vibration of the methylene group $\left(-\mathrm{CH}_{2}\right)$ or the methyl $\left(-\mathrm{CH}_{3}\right)$ and the absorption bands at $2889 \mathrm{~cm}^{-1}$ and $2923 \mathrm{~cm}^{-1}$ belongs to the homogeneous and heterogeneous extension vibration of the methylene group $\left(-\mathrm{CH}_{2}\right)$ or the methyl $\left(-\mathrm{CH}_{3}\right)$. The mentioned four peaks belong to the methylene group $\left(-\mathrm{CH}_{2}\right)$ and the methyl group $\left(-\mathrm{CH}_{3}\right)$ in the synthesis of amino acids, peptides or proteins and the sign of that is finding the absorption band returns to the single bond (C-C).

The spectrum also showed an absorption peak at $1620 \mathrm{~cm}^{-1}$ due to the extension vibration of the group $(\mathrm{C}=\mathrm{C})$ in the alkene compounds and to the successive double bonds in the benzene ring in the aromatic structures. The presence of compensated aromatic rings is found in the composition of amino acids, peptides, and proteins ${ }^{22}$. The peak of $2290 \mathrm{~cm}^{-1}$ is a clear indication of the existence of stylenyl derivatives contains trinal bonds $(\mathrm{C} \equiv \mathrm{C})$. From the other hand, the existence of other peaks mentioned supporting the presence of double bond $(\mathrm{C}=\mathrm{C})$ on carbon atoms at $1419 \mathrm{~cm}^{-1}$ and $3178 \mathrm{~cm}^{-1}$ related to the extension vibration of groups $\mathrm{C}-\mathrm{O}$ and $=\mathrm{C}-\mathrm{H}$ respectively, which is due to alk- 
ene compounds. Also, when reviewing the previous studies which studied the chemical composition of some Ginseng-derived compounds, it is certain that the extract in this study contains polyacetylenes may be in their three structures $^{1}$, (see Figure 7).

It is confirmed that the Ginseng extract contains polyacetylene compounds, amino acids, peptides, proteins, polyphenols, and polysaccharides. There is an extension vibration of the absorption bands at $3451 \mathrm{~cm}^{-1}$, and two bending vibration bands at $1261 \mathrm{~cm}^{-1}$ and $1359 \mathrm{~cm}^{-1}$ belong to the hydroxyl group (-OH) and the peak of $1419 \mathrm{~cm}^{-1}$ due to an extension vibration for the group C-O.

The absorption peak at $2705 \mathrm{~cm}^{-1}$ indicates the presence of hydrogen bound to the carbonyl group in the aldehyde group $(\mathrm{O}=\mathrm{C}-\mathrm{H})$. That is an evidence of the presence of non-cyclic monosugars. The two bands $603 \mathrm{~cm}^{-1}$ and $638 \mathrm{~cm}^{-1}$ showed the presence of the amide group $(\mathrm{O}=\mathrm{C}-\mathrm{N}-\mathrm{H})$ which binds successive two amino acids in the composition of proteins or peptides. Furthermore, the presence of the absorption peak at $3404 \mathrm{~cm}^{-1}$ also belongs to the amine group $(-\mathrm{NH})$ in the synthesis of the amino acid (Arginine), or belongs to the amide group in the peptide or protein synthesis ${ }^{22,23}$. The presence of the carboxylic group (-COOH) in amino acids is evidenced by the appearance of the broad absorption range from $2410 \mathrm{~cm}^{-1}$ to $3620 \mathrm{~cm}^{-1}$. Moreover, a bending vibration band at $925 \mathrm{~cm}^{-1}$ is belonging to the hydroxyl group in the carboxyl group ${ }^{24-27}$.

There is a band located at $1745 \mathrm{~cm}^{-1}$ belongs to hexagonal-cyclic ketones, thus it belongs to the group of Carbonyl $(\mathrm{C}=\mathrm{O})$. This is evidence that the extract contains flavonoids, which belong to the category of phenols and its function to protect the plant from the harmful effects of ultraviolet radiation. The presence of flavonoids in the Ginseng extract was studied by others as shown in Figure 8. That also confirms that the Ginseng extract under study contains these compounds. It is believed that because of the presence of hydroxyl $(-\mathrm{OH})$, carbonoxygen $(\mathrm{C}-\mathrm{O})$, methylene $\left(-\mathrm{CH}_{2}\right)$ and methyl $\left(-\mathrm{CH}_{3}\right)$ groups, the presence of ginsenoside compounds in the Ginseng extract is similar in structure to the primary structure of cholesterol but is more complex in terms of the chemical composition $^{28}$.

The FT-IR spectrum of the biosynthesized zinc nanoparticles (Figure 6B) shows the sharp absorption peak located at $1141 \mathrm{~cm}^{-1}$, the two clear peaks at $1371 \mathrm{~cm}^{-1}$ and $1423 \mathrm{~cm}^{-1}$ and the clear wideband at $1629 \mathrm{~cm}^{-1}$. That is a clear indicator to presence of nano-zinc atoms in the composition of the biosynthesized ZnNPs from Ginseng extract, because in a study on mushrooms found that the FTIR spectrum of silver nanostructures when it binds with the hydrocarbons, it shows four bands located nearby and within the mentioned ranges 
29. It was noted that this spectrum is very similar to the spectrum of FT-IR of the Ginseng extract (Figure 6A) in terms of the extension of the bands thus the chemical composition is similar, but the insulation, clarity, and the band width are better in the second spectrum (Figure 6B). The reason for this may be due to the presence of zinc atoms with good dispersion with a high surface area that enables the active groups in the electron-rich in the Ginseng extract to share their electron pairs with the empty orbitals in the outer shell of zinc.

It is known that zinc atoms have 30 electrons thus its fourth shell has one electronic pairs in the level (4s), thus the rest secondary levels $4 \mathrm{p}, 4 \mathrm{~d}$, and $4 \mathrm{f}$ which contain three, five, and seven orbitals respectively are empty and can assimilate coming electronic pairs from good atoms with negative charges are $\mathrm{O}, \mathrm{N}$, and $\mathrm{S}$ which find in monosaccharides, polysaccharides amino acids, peptides, proteins, polyphenols, flavonoids, polyacetylenes, and ginsenosides. Thus, the previous FT-IR spectrum (Figure 6B) exhibited that the structures of acidic polysaccharides, amino acids, ginsenosides, poly acetylenes, and polyphenols in the Panax ginseng extract are not affected because of interaction their active groups with zinc ions or zinc nanoparticles as reducing and capping agents to the synthesized ZnNPs.

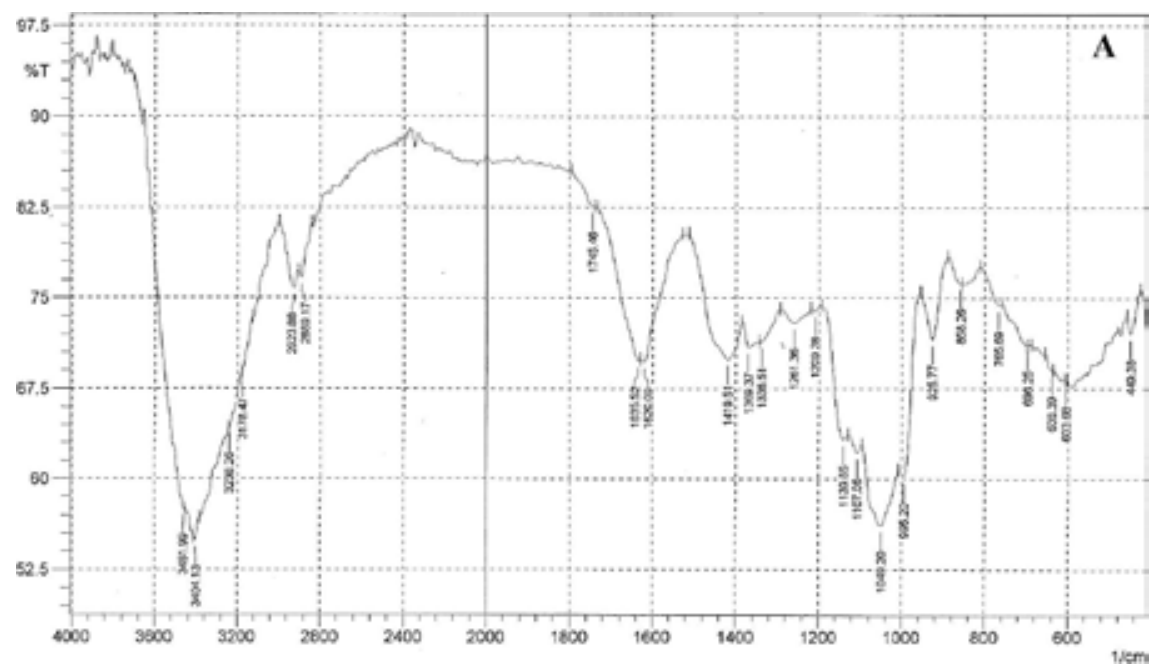




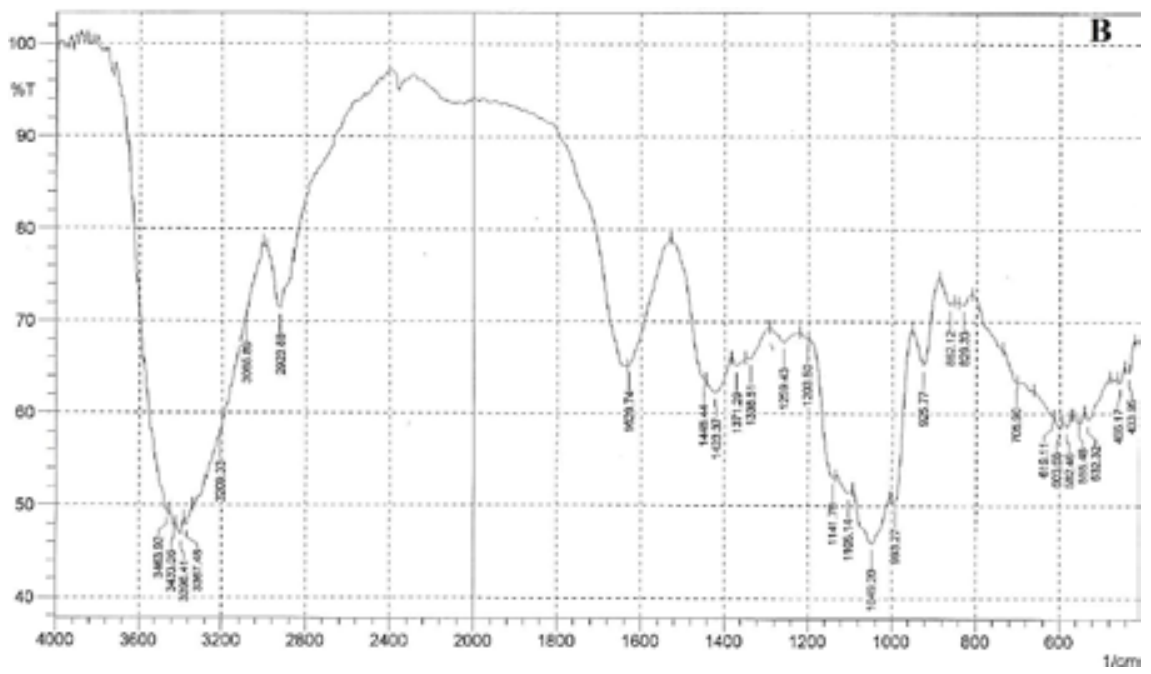

Figure 6. FT-IR spectrum of extract of $P$. ginseng (A) extract and ZnNPs of $P$. ginseng (B)<smiles>C=CC(O)C#CC#C[C]C/C=C\CCCCCCC</smiles><smiles>C=CC(O)C#CC#CC[C]C1OC1CCCCCCC</smiles><smiles>C=CC(O)C#CC#CC[C]C(O)=C(O)CCCCCCC</smiles>

Figure 7. Structures of polyacetylene compounds expected in the extract of Ginseng ${ }^{1}$<smiles>O=c1cc(-c2ccccc2)c2ccccc2o1</smiles><smiles>O=c1cc(-c2ccccc2)oc2ccccc12</smiles>

Figure 8. Two structures of flavonoids compounds expected in the extract of Ginseng 
Cytotoxicity of the biosynthesized ZnNPs and extracts of Panax ginseng Ginseng were applied against L2OB tumor cell line using the colorimetric cell viability MTT assay. Three concentrations (50\%, 75\%, and 100\%) of ZnNPs solution and aqueous extracts of Ginseng were individually achieved compared with the control. All concentrations of aqueous crude extracts did not exhibit any growth inhibition percentage as shown in Figure 9. Zinc nanoparticles of Ginseng showed growth inhibition percentages approx. 35.03\%. The concentration of $100 \%$ significantly $(p<0.01)$ recorded inhibition percentage of $41.70 \%$, followed $33.30 \%$ and $30.10 \%$ by the concentration $75 \%$ and $50 \%$ respectively. The reason of that belongs to induce cytotoxicity and ROS generation in L2OB tumor cell line ${ }^{30}$ which cause apoptosis leading to cell death and preventing their replication. ${ }^{31}$. Extract of $P$. ginseng composes from some pharmacological compounds like polysaccharides, flavonoids, triterpenoids, and ginsenosides which caped ZnNPs, have been included anticancer activity ${ }^{1,10,11}$. The ability of the biosynthesized ZnNPs to inhibit L2OB tumor cell line is considered as a potential indicator for biological activity of these green nanoparticles against the cancers in vitro. Saponin of Red Ginseng roots (Ginsenoside) is active compound against cancers ${ }^{32}$ because of its role as antioxidant agent covering the ZnNPs. The zinc in many medical and nutritional products play a promising role in host defense to prevent the initiation, promotion and development of carcinoma. ${ }^{33} \mathrm{~A}$ zinc nanoparicle model is useful as an approach to increase activity of zinc in treatment of cancers due to the high surface area of ZnNPs. Many studies were investigating the inhibitory role of AgNPs toward human cancers but not ZnNPs. These results agree with results of ${ }^{12}$ who refereed to that silver nanoparticles of Ginseng decreased the levels of mRNA and phosphorylation of receptors of epidermal growth factor in cancer cells. While ${ }^{14}$ prepared gold nanoparticles from this plant and have antioxidant effects. 


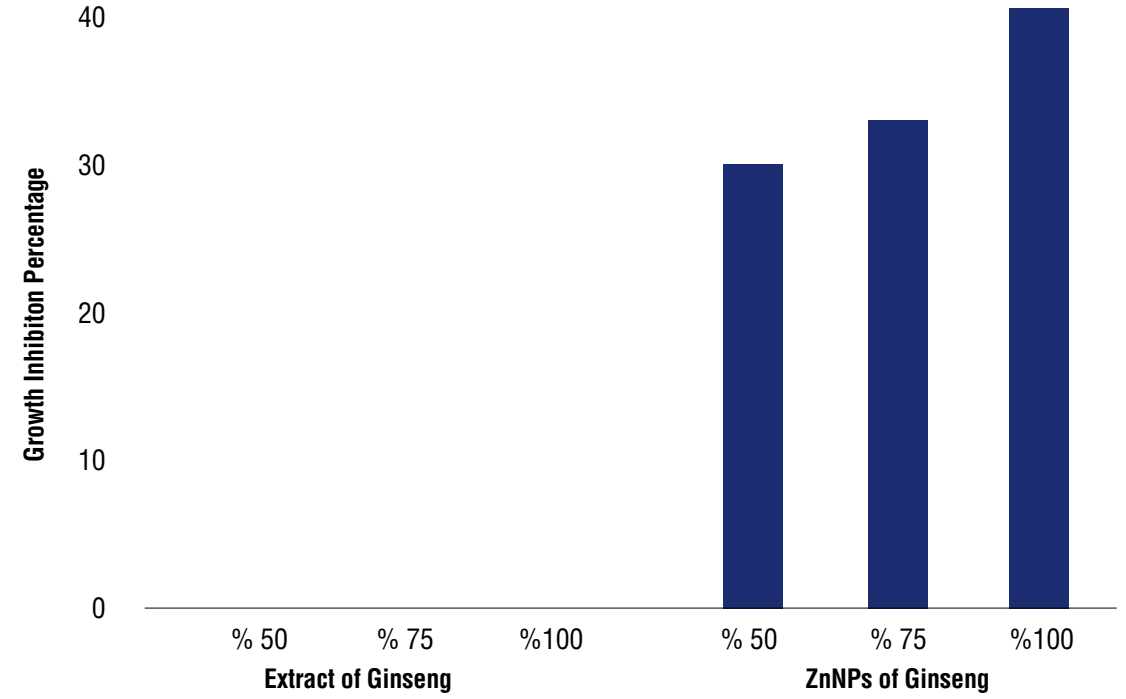

Figure 9. Cytotoxicity of extract of ginseng (P. ginseng) and its biosynthesized ZnNPs

\section{CONCLUSION}

This study aims to biosynthesize zinc nanoparticles from the aqueous extract of Panax ginseng (Red Ginseng) roots and characterize their properties. SEM image observes shapes of zinc nanoparticles which are spherical to irregular particles with rate of size $59.76 \mathrm{~nm}$. The FT-IR spectrum of ZnNPs exhibited that the numerous structures of acidic polysaccharides, amino acids, ginsenosides, polyacetylenes, and polyphenols in the Ginseng extract are not affected because of interaction their active groups to reduce and cap zinc ions to $\mathrm{Zn}^{\circ}$ and synthesizing zinc nanoparticles (ZnNPs). EDS reconfirmed that the nanoparticles formed are indeed metal ZnNPs. The concentration 100\% Zinc nanoparticles significantly $(p<0.01)$ recorded best inhibition percentage $41.70 \%$ against murine fibroblast cells (L2OB) which have receptors of human polioviruses, thus, this work is considered as an auspicious first test to reduce the growth of cancers using green ZnNPs of Ginseng (Panax ginseng) in vitro. A zinc nanoparticle model is useful as an approach to increase activity of zinc in treatment of cancers due to the high surface area of ZnNPs.

\section{ACKNOWLEDGMENTS}

Authors are thanking the staff of Department of Ecology, College of Applied Sciences-Heet in University of Anbar to achievement this project No. 4/122 on 15 Oct 2017. Special thanks to University of Baghdad and Al-Nahrain University for contribution in completing the cytotoxicity assay. 


\section{REFERENCES}

1. SM Lee, B Bae, H Park, N Ahn, B Cho, Y Cho and Y Kwak. Characterization of Korean Red Ginseng ( Panax ginseng Meyer ): History, preparation method, and chemical composition. J Ginseng Res. 2015, 39, 384-391. doi:10.1016/j.jgr.2015.04.009.

2. Y Kim, J Jeon, M-G Jang, J Oh, W-S Kwon, S-K Jung, D-C Yang. Ginsenoside profiles and related gene expression during foliation in Panax ginseng Meyer. $J$ Ginseng Res. 2014, 38 , 66-72.

3. H Jeong, H Hong, Y Kim, J Rho, K Kim and C Cho. The research trend of ginseng processing technology and the status of ginseng industry. Food Sci Ind. 2012, 45, 59-67.

4. W Yang, Y Hu, W Wu, M Ye and D Guo. Phytochemistry Saponins in the genus Panax L . ( Araliaceae ): A systematic review of their chemical diversity. Phytochemistry. 2014, 106, $7-24$.

5. S Kang and H Min. Ginseng, the 'immunity boost': the effects of Panax ginseng on immune system. J Ginseng Res. 2012, 36, 354-368.

6. A Attele, J Wu and C Yuan. Ginseng pharmacology: multiple constituents and multiple actions. Biochem Pharmacol. 1999, 58, 1685-1693.

7. S Lam and T Ng. Isolation of a small chitinase-like antifungal protein from Panax notoginseng (sanchi ginseng) roots. Int J Biochem Cell Biol. 2001, 33, 287-292.

8. J Xie, S McHendale and S Yuan. Ginseng and diabetes. Am J Chin Med. 2oo5, 33, 397404.

9. G Yang, D Park, J Lee, B Song, T Jeon, S Kang, J Jeon, S Shin, H Jeong, H Lee and Y Kim. Suppressive effects of red ginseng preparation on SW480 colon cancer xenografts in mice. Food Sci Biotechnol. 2011, 20, 1649-1653.

10. CH Lee and J Kim. Review article A review on the medicinal potentials of ginseng and ginsenosides on cardiovascular diseases. J Ginseng Res. 2014, 38, 161-166. doi:10.1016/j. jgr.2014.03.001.

11. C Cho, Y Kim, YK Rhee, Y Lee and K Kim. Chemical composition characteristics of Korean straight ginseng products. $J$ Ethn Foods. 2014, 1, 24-28. doi:10.1016/j.jef.2014.11.007.

12. V Castro-Aceituno, S Ahn, SY Simu, P Singh, R Mathiyalagan, HA Lee and DC Yang. Anticancer activity of silver nanoparticles from Panax ginseng fresh leaves in human cancer cells. Biomed Pharmacother. 2016, 84, 158-165. doi:10.1016/j.biopha.2016.09.016.

13. P Singh, Y Kim and D Yang. A strategic approach for rapid synthesis of gold and silver nanoparticles by Panax ginseng leaves. Artif Cell Nanomed B. 2016, 44, 1949-1957.

14. ZE Jiménez-pérez, P Singh, Y Kim, R Mathiyalagan, D Kim, MH Lee and DC Yang. Applications of Panax ginseng leaves-mediated gold nanoparticles in cosmetics relation to antioxidant , moisture retention , and whitening effect on B16BL6 cells. J Ginseng Res. 42 (3) 2017, 1-7. doi:10.1016/j.jgr.2017.04.003.

15. MA Willard, LK Kurihara, EE Carpenter, S Calvin and VG Harris. Chemically prepared magnetic nanoparticles. Int Mater Rev. 2004, 49, 125-170.

16. A Hernandezbattez, R Gonzalez, J Viesca, J Fernandez, J Diazfernandez, A MacHado, R Chou and $\mathrm{J}$ Riba. $\mathrm{CuO}, \mathrm{ZrO} 2$ and $\mathrm{ZnO}$ nanoparticles as antiwear additive in oil lubricants. Wear. 2008, 265, 422-428. 
17. PL Chih, JT Wei, LL Yuang and CK Yuh. The extracts from Nelumbonucifera suppress cell cycle progression, cytokine genes expression, and cell proliferation in human peripheral blood mononuclear cells. Life Sci. 2004, 75, 699-716.

18. RI Freshney. Culture of Animal Cell. 6th ed., Wily-Liss, New York, 2012.

19. U Rajamanickam, S Viswanathan and P Muthusamy. Biosynthesis of Zinc Nanoparticles Using Actinomycetes for Antibacterial Food Packaging. in: Int Conf Nutr Food Sci IPCBEE, IACSIT Press, Singapore, 2012, pp. 195-199.

20. C Burda, X Chen, R Narayanan and MA El-Sayed. Chemistry and properties of nanocrystals of different shapes. Chem Rev. 2005, 105, 1025-1102.

21. L Jia, Q Zhang, Q Li and H Song. The biosynthesis of palladium nanoparticles by antioxidants in Gardenia jasminoides Ellis : long lifetime nanocatalysts for $\mathrm{p}$-nitrotoluene hydrogenation. Nanotechnology. 2009, 2O, 0-9. doi:10.1088/0957-4484/20/38/385601.

22. BD Mistry. A Handbook of Spectroscopic Data CHEMISTRY (UV, JR, PMR, JJCNMR and Mass Spectroscopy). 2009th ed., Oxford Book Company, 2009.

23. R Silverstein, F Webster and D Kiemle. Spectrometric identification of organic compounds. 7th ed., John Wiley and sons, Inc., London, UK, 2005.

24. LD Field, S Sternhell and JR Kalman. Organic Structures from Spectra. 4th ed., John Wiley and Sons Ltd, 2008.

25. K Nakamoto. Infrared and Raman Spectra of Inorganic and Coordination Compounds Part A: Theory and Applications in Inorganic Chemistry. 6th ed., A John Wiley and Sons, Inc., 2009.

25. J Simek. Organic Chemistry. 8th ed., Pearson education, Inc., 2013.

27. OH Abid, HM Tawfeeq and RF Muslim. Synthesis and Characterization of Novel 1,3-oxazepin-5(1H)-one Derivatives via Reaction of Imine Compounds with Isobenzofuran-1(3H)one. Acta Pharm Sci. 2017, 55, 43-55.

28. D-H Kim. Chemical Diversity of Panax ginseng, Panax quinquifolium , and Panax notoginseng. $J$ Ginseng Res. 2012, 36, 1-15.

29. S Sujatha, S Tamilselvi, K Subha and A Panneerselvam. Studies on biosynthesis of silver nanoparticles using mushroom and its antibacterial activities. Int J Curr Microbiol App Sci. 2013, 2, 605-614.

30. DR Nogueira, CMB Rolim and AA Farooqi. Nanoparticle induced oxidative stress in cancer cells: adding new pieces to an incomplete jigsaw puzzle. Asian Pac $J$ Cancer Prev. 2014, $15,4739-4743$.

31. KS Siddiqi, A Husen and RAK Rao. A review on biosynthesis of silver nanoparticles and their biocidal properties. $J$ Nanobiotechnology. 2018, 16(14), 174-201. doi:10.1186/s12951018-0334-5.

32. C-Z Wang, HH Aung, M Ni, J-A Wu, R Tong, S Wicks, T-C He and C-S Yuan. Red American Ginseng: Ginsenoside Constituents and Antiproliferative Activities of Heat-Processed Panax quinquefolius Roots. Planta Med. 2009, 73, 669-674. doi:10.1055/s-2007-981524. Red

33. D.K. Dhawan and V.D. Chadha. Zinc: A promising agent in dietary chemoprevention of cancer. Indian J Med Res. 2010, 132, 676-682. doi:10.2147/IJN.S16581. 